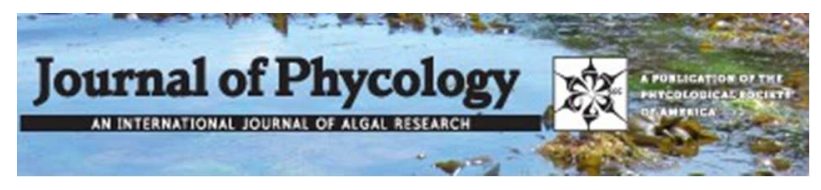

\title{
GENE SILENCING IN FUCUS EMBRYOS: DEVELOPMENTAL CONSEQUENCES OF RNAI-MEDIATED CYTOSKELETAL DISRUPTION.
}

\begin{tabular}{|r|l|}
\hline Journal: & Journal of Phycology \\
\hline Manuscript ID: & JPY-12-279-ART.R1 \\
\hline Manuscript Type: & Regular Article \\
\hline Date Submitted by the Author: & 11 -May-2013 \\
\hline Complete List of Authors: & $\begin{array}{l}\text { Brownlee, Colin; Marine Biological Association, ; } \\
\text { Farnham, Garry; Marine Biological Association, } \\
\text { Strittmatter, Martina; UPMC University Paris 06, } \\
\text { Coelho, Susana ; CNRS, UMR 7139, Station Biologique de Roscoff, } \\
\text { Cock, J. Mark; Station Biologique de Roscoff, UMR 7139 }\end{array}$ \\
\hline Keywords: & gene silencing, brown algae, Fucus, RNAi, cytoskeleton, tubulin, actin \\
\hline
\end{tabular}



GENE SILENCING IN FUCUS EMBRYOS: DEVELOPMENTAL CONSEQUENCES OF RNAi-MEDIATED CYTOSKELETAL DISRUPTION.

Garry Farnham*,

5 Marine Biological Association, The Laboratory, Citadel Hill, Plymouth PL1 2PB, UK

CNRS, UMR 7139, and UPMC University Paris 06, The Marine Plants and Biomolecules

Laboratory, UMR 7139, Station Biologique de Roscoff, Place Georges Teissier, BP74, 29682 Roscoff Cedex, France.

Marine Biological Association, The Laboratory, Citadel Hill, Plymouth PL1 2PB, UK.

School of Ocean and Earth Sciences, University of Southampton, National Oceanography

${ }^{1}$ Author for correspondence: email cbr@mba.ac.uk 
1

2

Abstract

Brown algae (Phaeophyta) are an important algal class that play a range of key ecological roles. They are often important components of rocky shore communities. A number of members of the Fucales and Ectocapales have provided models for the study of multicellular evolution, reproductive biology and polarised development. Indeed the fucoid algae exhibit the unusual feature of inducible embryo polarisation, allowing many classical studies of polarity induction. The potential of further studies of brown algae in these important areas has been increasingly hindered by the absence of tools for manipulation of gene expression that would facilitate further mechanistic analysis and gene function studies at a molecular level. The aim of this study was to establish a method that would allow the analysis of gene function through RNAi-mediated gene knockdown. We show that injection of dsRNA corresponding to an $\alpha$-tubulin gene into Fucus serratus zygotes induces the loss of a large proportion of the microtubule cytoskeleton, leading to growth arrest and disruption of cell division. Injection of dsRNA targeting $\beta$-actin led to reduced rhizoid growth, enlarged cells and the failure to develop apical hair cells. The silencing effect on actin expression was maintained for three months. These results indicate that the Fucus embryo possesses a functional RNA interference system that can be exploited to investigate gene function during embryogenesis. 


\section{Introduction}

4 The brown algae are an important group of organisms that dominate the flora of many rocky shore environments. These organisms have attracted interest for a number of reasons, including their capacity to synthesise novel biomolecules (McHugh 2003; Klarzynski et al. 2003), as models for the study of early embryogenesis (Brownlee et al. 2001) and as one of the few major eukaryotic groups that has evolved complex multicellularity (Cock et al. 2010a). Brown algae belong to the stramenopile group, which also includes the diatoms and the oomycetes, and are hence only very distantly related to classical laboratory model organisms such as Drosophila and Arabidopsis. There is a pressing need to adapt tools that have been developed for such classical model organisms to brown algal systems in order to investigate the unusual biological features of these seaweeds. However, to date no reports of gene knock down or manipulation of gene expression have been reported for any brown algal species. This represents a major bottleneck in further development of brown algal models.

Small, 18-30 nucleotide RNA molecules derived by nuclease digestion of larger doublestranded or hairpin RNA molecules play important regulatory roles in cells including defending the genome against mobile elements, chromatin regulation and modulation of gene expression \{Carthew and Sontheimer 2009; Vionnet 2009; Chapman and Carrington 2007). The RNA interference (RNAi) system, which is mediated by small interfering RNAs (siRNAs), has been exploited in many different model organisms in order to develop gene knockdown systems and has proven to be a powerful tool to investigate gene function.

RNAi was initially characterised in green plants and animals (Carthew and Sontheimer 2009;

Voinnet 2009) but it is becoming increasingly clear that this is a very ancient cellular system 
that is present in a broad range of eukaryotic groups. For example, proteins resembling key components of the RNAi machinery, such as dicer, argonaute and RNA-dependent RNA polymerase (RdRP) have been identified in almost all of the major eukaryotic lineages (Cerutti et al. 2011) and small RNA molecules have been characterised from a broad range of species, including stramenopiles (Cock et al. 2010a; Norden-Krichmar et al. 2011; Huang and Wang 2011). The genome of the brown alga Ectocarpus, for example, appears to encode all the above components of the RNAi machinery together with a broad range of small RNAs including microRNAs (Cock et al. 2010a). Moreover, the potential of RNAi as a tool for investigating gene function in stramenopiles was recently demonstrated in two studies that used this approach to investigate light signalling pathways in the yellow-green alga Vaucheria frigida (Takahashi et al. 2007) and the diatom Phaeodactylum tricornutum (De Riso et al. 2009).

The aim of the work described here was to investigate whether RNAi could be used to knock down gene function in a brown alga. Experiments were carried out using a fucoid species, Fucus seratus, for several reasons. First, this group of brown algae produce large zygotes allowing double stranded RNA (dsRNA), the substrate for the production of siRNAs, to be introduced directly by microinjection. Second, the cellular events associated with early embryogenesis have been investigated in detail in this group of brown algae and a number of molecules involved in this process have been identified (Corellou et al. 2005; Fowler et al. 2004; Brownlee et al. 1998, 2001). These previous studies, therefore, both provide potential targets for RNAi knockdown and a reference framework that allows identification and characterisation of deviations from the normal process of embryogenesis. The roles of cytoskeletal components in determining polarity and division pattern during early embryogenesis has been particularly well characterised in fucoid zygotes and embryos (reviewed in Bisgrove, 2007; Brownlee et al. 2001). Fixation of the polar axis depends on the 
1 localization of F-actin at the presumptive rhizoid apex and rhizoid germination is dependent

2 on a functional actin cytoskeleton but is independent of the microtubule polymerization

3 (Corellou et al, 1995; Hable et al, 2003). Microtubule connections between the growing

4 rhizoid apex and the mitotic apparatus ensure appropriate alignment of the division axis

5 (Peters and Kropf, 2010; Bisgrove et al. 2003). Mitotic divisions are associated with

6 substantial dynamics of the microtubule cytoskeleton (e.g. Corellou et al. 2005; Hable et al.

7 2003). We show that microinjection of Fucus serratus zygotes with dsRNA corresponding to

$\alpha$-tubulin leads to growth inhibition and disruption of cell division in a manner consistent

with that observed following treatment with the microtubule depolymerising molecule nocodazole. Moreover, immunocytochemistry revealed that injection with the $\alpha$-tubulin

dsRNA led to a dramatic reduction in the cellular levels of $\alpha$-tubulin and disruption of microtubule cytoskeletal dynamics. Injection of dsRNA targeting $\beta$-actin produced substantially different long-lasting morphological responses that included inhibited rhizoid growth, multicellular embryos with enlarged cells and the failure to develop apical hair cells.

\section{MATERIALS AND METHODS}

Biological material. Collection of fertile Fucus serratus individuals, gamete production, fertilization and embryo culture were carried out as described previously (Corellou et al. 2005). Briefly, gamete release was triggered by immersing receptacles in fresh water for several minutes before transferring to filtered seawater (FSW) at $15-18^{\circ} \mathrm{C}$ and a light intensity of $70 \mu \mathrm{mol} \mathrm{s}{ }^{-1}$. Released gametes (eggs and spermatozoids) were filtered through a $100 \mu \mathrm{m}$ nylon mesh. Eggs were washed gently with FSW before addition of sperm, washed with FSW to remove excess sperm after $30 \mathrm{~min}$. and incubated at $18^{\circ} \mathrm{C}$ at a light intensity of $70 \mu \mathrm{mol} \mathrm{m}$ ${ }^{2} \mathrm{~s}^{-1}$ for $1 \mathrm{~h}$. Following fertilization, zygotes were transferred to microinjection dishes in FSW 
and kept on ice in the dark until microinjection, which was either carried out on the same or the following day.

Plasmid constructs. ORF Esi0053_0070 of the Ectocarpus genome (add REF Cock et al., 2010), which is predicted to encode $\alpha$-tubulin, was used in a nucleotide BLAST search to interrogate a $F$. serratus EST data set (Pearson et al. 2010). The best hits were to a contig designated TC_00471 that aligned with 750 bp of the Esi0053_0070 coding sequence (90\% identity). PCR primers MB1 (TGCGGTATCAACTACCAGCC) and MB2 (ATACAGCTTCTCATAGCATAGG) were designed to amplify a region consisting of 306 bp of the predicted $\alpha$-tubulin protein coding sequence and 236 bp of the 3'UTR in TC_00471. A second contig, designated TC_00244 was also identified. In the 306 bp region spanning the MB1 primer binding site in TC_00471 to the end of the predicted $\alpha$-tubulin coding sequence there are 15 variant nucleotides between the two sequences. In contrast, the $239 \mathrm{bp}$ region spanning the 3'UTR of TC_00471 to the primer binding site MB2 has no identical regions greater than $5 \mathrm{bp}$ and MB2 does not match any sequences in this region of TC_00244 (Fig. S1). Thus the F. serratus genome contains at least 2 tubulin genes, only one of which (TC_00471) was investigated in this study. Total RNA was extracted from desiccated $24 \mathrm{~h} F$. serratus embryos using the method of Pearson (Pearson et al. 2010). First strand cDNA synthesis was performed using $1 \mu \mathrm{g}$ of $F$. serratus RNA, an oligo dT(18) primer and Invitrogen Superscript III reverse transcriptase as per manufacturers recommendations. A 542 bp fragment corresponding to the $F$. serratus $\alpha$-tubulin mRNA sequence was amplified with TAQ DNA polymerase using primers MB1 and MB2 and $1 \mu 1$ of first strand cDNA. The complete $F$. serratus $\beta$-actin mRNA sequence including 69 bp of the 5'UTR and $157 \mathrm{bp}$ of the 3'UTR was determined by RACE PCR (Fig. S2). Primers ACTFS1 (5'-

ATGGCGGACGAGGACGTG-3') and ACTFS2 (5'-CGCCCGGCGAGGTCGAG-3') were used to generate a 551bp product starting at the ATG start codon. Additionally, primers MB3 
(CACTCTTGTACTCCACCTTC) and MB4 (TTAGAAGCACTTGCGGTG) were designed to amplify a region spanning $69 \mathrm{bp}$ of the 5'untranslated region and the entire $1131 \mathrm{bp}$ coding sequence including the stop codon in order to generate the $1200 \mathrm{bp}$ fragment. All products were cloned into pCR2.1 TOPO and the nucleotide sequence and orientation relative to the T7 promoter was confirmed by sequencing individual clones in both directions. Plasmid constructs used in subsequent procedures, designated pCR2.1 TOPO:Tubulin1 (sense to T7 promoter), pCR2.1 TOPO:Tubulin 4 (antisense), pTOPO:GF actin (sense; $1200 \mathrm{bp}$ fragment) and pTOPO:GF (antisense; $1200 \mathrm{bp}$ fragment), pTOPO:LD actin (sense; $551 \mathrm{bp}$ fragment) and pTOPO:LD (antisense; 551 bp fragment) were harvested from E. coli Top10 cells (Invitrogen) using Qiagen miniprep columns, linearized with BamHI and subjected to a proteinase K/SDS treatment followed by phenol chloroform extraction (Sambrook and Russel) to reduce RNAse contamination.

Synthesis of double-stranded (ds) RNA. Synthesis of dsRNA by T7 polymerase transcription was carried out using the MEGAscript ${ }^{\circledR}$ RNA kit (Ambion, Life Technologies) according to the manufacturer's instructions. For the transcription reaction, $1 \mu \mathrm{g}$ of each plasmid (sense and antisense) was used in a single $20 \mu \mathrm{l}$ reaction. The reaction was incubated for $4 \mathrm{~h}$ at $37^{\circ} \mathrm{C}$ and this was followed by an annealing step in which the sample was heated to $90^{\circ} \mathrm{C}$ for $5 \mathrm{~min}$ followed by gradual cooling to $20^{\circ} \mathrm{C}$ at a rate of $0.2^{\circ} \mathrm{C} \mathrm{s}^{-1}$. The quality of the dsRNA was checked by agarose gel electrophoresis and the concentration was determined on a NanoDrop 1000 spectrophotometer (Thermo Scientific, Cramlington, UK). The $551 \mathrm{bp}$ and $1200 \mathrm{bp}$ Actin dsRNA constructs gave the same phenotype but we found that the Megascript derived dsRNA from the $1200 \mathrm{bp}$ template was more abundant than dsRNA deriving from the 551bp template. Therefore the former was used in the $\beta$-actin silencing experiments we describe here. 
Microinjection of dsRNA. F. serratus zygotes were secured in glass wedges formed from a 1 $\mathrm{cm}$ length piece of glass capillary (microdispenser $250 \mu \mathrm{L}$ replacement tubes; Drummond Scientific, Broomall, PA, USA) glued onto a glass coverslip. The zygotes were then immersed in FSW containing 0.4 M sorbitol in order to decrease turgor pressure. The $0.4 \mathrm{M}$ sorbitol was then replaced by $0.8 \mathrm{M}$ sorbitol and zygotes were microinjected at $18^{\circ} \mathrm{C}$ using a pressure system (Corellou et al. 2005). The microinjection pipettes were made from $1.2 \mathrm{~mm}$ filamented borosilicate glass (Clarke Electromedical, Reading, UK), dry-beveled and back filled with 10 $\mu \mathrm{L}$ of artificial intracellular solution (200 mM KCl, $10 \mathrm{mM}$ Hepes, $550 \mathrm{mM}$ mannitol, $\mathrm{pH}$ 7) containing $0.1 \mathrm{mM}$ fluorescein isothiocyanate (FITC) and $10 \mathrm{ng} \mu \mathrm{L}^{-1}$ dsRNA (dsRNA:tubulin, dsRNA:actin or dsRNA:control). The microinjection process was monitored by observing FITC fluorescence (450 nm excitation, $510 \mathrm{~nm}$ emission) so that the volume microinjected corresponded to about 5-10\% of the zygote cell volume. Following microinjection the zygotes were kept in the dark at $18^{\circ} \mathrm{C}$ and the sorbitol solution was gradually replaced with FSW. The dishes were then transferred to and placed in unidirectional light at $18^{\circ} \mathrm{C}$. The following day (19-24 h after microinjection), the development of injected zygotes was scored and images obtained using a CCD camera (DCM A series; ScopTek, Kelowna, BC, Canada) on an Axiovert microscope (Zeiss, Jena, Germany). Both dsRNA:control (positive non-coding sequence control supplied with the Ambion Megascript kit) and dsRNA:tubulin or dsRNA:actin injections were carried out during each microinjection session.

Immunolabeling and confocal microscopy. Immunolabeling of $\alpha$-tubulin was carried out between 19 and $24 \mathrm{~h}$ after the microinjection of dsRNA. The protocol was as described by Bisgrove and Kropf (2001), with the following modifications. The initial step of freezing the material in liquid nitrogen was omitted since this step usually led to considerable loss of injected $F$. serratus zygotes. The material was incubated in freshly prepared fixation solution (FSW containing $0.5 \% \mathrm{v} / \mathrm{v}$ glutaraldehyde and $3.2 \% \mathrm{v} / \mathrm{v}$ formaldehyde) for $1 \mathrm{~h}$ and then 
1 rinsed three times for $5 \mathrm{~min}$ in modified PBS before incubating in 5\% v/v Triton X-100 overnight. The following day, the material was washed again in mPBS and incubated for $4 \mathrm{~h}$ in $0.1 \mathrm{M} \mathrm{NaBH}_{4}$ in mPBS. After washing in mPBS the material was rinsed in solution $\mathrm{C}$, then incubated in solution $\mathrm{C}(100 \mathrm{mM} \mathrm{NaCl}, 20 \mathrm{mM} \mathrm{MgCl} 2,2 \mathrm{mM} \mathrm{KCl}, 0.2 \% \mathrm{BSA}, 10 \mathrm{mM}$ MES, $0.85 \mathrm{M}$ sorbitol, $1 \mathrm{mM}$ EGTA, with $\mathrm{pH}$ adjusted to 5.8 with Tris base), containing hemicellulase (40 mg/mL; Sigma H2125) and cellulase (7 mg/mL; Sigma C8546) for $90 \mathrm{~min}$ and washed in mPBS. Anti- $\alpha$-tubulin (Sigma, T9026) was used at a dilution of 1/50 in 250$500 \mu \mathrm{L}$ mPBS and the secondary antibody (rhodamine-conjugated goat anti-mouse IgG; Pierce Thermo Scientific) was used at a dilution of 1/100 in mPBS. All incubation steps were performed at room temperature. Confocal sections of rhodamine fluorescence were obtained with a Zeiss LM510 confocal laser scanning microscope with a $x 40,1.3$ n.a. objective using four line averaging (image size 512 x 512 pixels, 8 bit). $\mathrm{Z}$ stacks were viewed as planar projections using the Zeiss LSM software.

Quanitification of fluorescent signal and microtubules. In order to estimate the levels of $\alpha-$ tubulin, we measured the fluorescence of immunolabeled Fucus zygotes from planar projections of confocal sections of dsRNA:tubulin-injected, dsRNA:control-injected and uninjected samples. Quantification was performed using ImageJ software (http://rsbweb.nih.gov/ij/). Two quantification methods were employed. First the mean gray value (equivalent to the sum of pixel intensities divided by the number of pixels) of the complete embryo was measured. We also determined the relative area of microtubules. A standard threshold look up table was applied to each image to maximize the contrast of microtubule fluorescence. Binary images of pixels above and below the threshold value were used to determine the relative area occupied by microtubules. The data were analyzed using GraphPad Prism version 5.03 for Windows and significance $(\mathrm{p}<0.05)$ was determined by 
applying Kruskal Wallis and Dunn's multiple comparison post test. In total, images of three independent experiments were analyzed in this way.

Length measurements. Lengths of developing F. serratus zygotes and embryos from the thallus apex to the rhizoid tip were measured as a proxy of growth using a measuring microscope ocular. Measurements of dsRNA:control, dsRNA:tubulin and uninjected zygotes were made $1 \mathrm{~d}(19-24 \mathrm{~h}), 2 \mathrm{~d}(40-43 \mathrm{~h})$ and $3 \mathrm{~d}(64-67 \mathrm{~h})$ after injection in two independent experiments.

Nocodazole treatment. Nocodazole was dissolved in DMSO to a concentration of $5 \mathrm{mg} \mathrm{ml}^{-1}$ and further diluted in FSW to a final concentration of $1 \mu \mathrm{g} \mathrm{ml}^{-1}$. Zygotes were incubated in nocodazole for $3 \mathrm{~d}$ and the medium containing the inhibitor was changed daily. Zygotes incubated in $0.02 \%(\mathrm{v} / \mathrm{v})$ DMSO served as controls and were treated in the same manner.

\section{Results}

Effects of tubulin dsRNA injection on rhizoid growth and embryonic cell divisions. Disruption of the microtubule cytoskeleton in Fucus zygotes with pharmacological agents such as nocodazole or colchine leads to characteristic abnormal developmental phenotypes including inhibition of rhizoid growth and aberrant cell divisions (Corellou et al. 2005, Katsaros et al. 2006; Quatrano, 1973). We tested whether introduction of tubulin dsRNA into Fucus zygotes could induce similar effects. F. serratus zygotes were microinjected with either Fucus dsRNA:tubulin or with dsRNA:control (dsRNA corresponding to a non-coding sequence supplied with the Ambion Megascript kit). The length of the developing zygotes and embryos (from the apical thallus region to the rhizoid tip) was measured daily as a proxy for tip growth (Figure 1). No differences in zygote length were observed between the different treatments prior to $24 \mathrm{~h}$ post-injection (PI) (Fig. 1a). However, the dsRNA:tubulin injected embryos, 
1

grew more slowly over the following $2 \mathrm{~d}$ and in most cases no increase in length was detected after $3 \mathrm{~d}$ PI. In contrast, the dsRNA:control-injected zygotes grew continuously, in a manner comparable to uninjected zygotes. Three d after injection of dsRNA:tubulin, embryos showed loss of pigmentation and increased vacuolation, indicating that they were becoming senescent (Fig. 1b). Moreover, the rhizoids of the dsRNA:tubulin-injected zygotes appeared swollen and misshapen (Figs. 1b and 2f-h). Similar rhizoid phenotypes were observed when Fucus zygotes were incubated with nocodazole, an inhibitor of microtubule polymerization (Fig. 2b-d).

\section{Cell division and cell plate formation in dsRNA injected zygotes. Cell plate formation was} monitored in developing embryos using normal light field microscopy $19-24 \mathrm{~h}$ after injection with dsRNA. The observed phenotypes could be classified into four different categories (Fig. 3): a) Normal cell plate formation with regard to the developmental stage of the zygote as described in the literature (e.g. Goodner and Quatrano 1993; Bouget et al. 1998), b) absence of cell plate formation, c) aberrant, but symmetrical cell plate formation and d) aberrant, asymmetrical cell plate formation (atypical division patterns and/or incomplete cell plate formation). Only $25.5 \%$ of the dsRNA:tubulin injected zygotes exhibited normal cell plate formation, compared with $90.2 \%$ of the uninjected controls (Fig. 3e). The zygotes injected with dsRNA:control showed a slightly lower frequency of normal cell plate formation (73.1\%) than the uninjected controls but the effect was much less marked than in the dsRNA:tubulin injected sample. Both the dsRNA:tubulin and dsRNA:control injected zygotes included a proportion of individuals with aberrant cell plate formation. However, in contrast to the dsRNA:tubulin injected zygotes, the aberrant cell plates observed in dsRNA:controlinjected zygotes were always symmetrical, whereas $41.8 \%$ of the dsRNA:tubulin-injected Fucus zygotes showed cell plates that were not only aberrant, but also asymmetrical and incomplete. A small percentage of Fucus egg cells may be fertilised by more than one male gamete (polyspermy) (Brawley 1987). The presence of more than one pair of paternal 
1

centrioles in these zygotes causes aberrant positioning of the cell division planes (Bisgrove et al. 2003; Motomura and Nagasato 2004). This may explain the small percentage of embryos with aberrant, but symmetrical, cell division patterns observed following dsRNA:control microinjection (Fig. 3 c, e), assuming that polyspermy levels were high in this sample due to the presence of a large number of male gametes during fertilisation. The proportion of embryos that completely failed to form a cell plate was markedly higher in dsRNA:tubulininjected zygotes (32.7\%) compared to control-injected $(11.5 \%)$ and uninjected $(4.8 \%)$ embryos.

Reduced microtubule abundance and aberrant microtubule organisation in zygotes injected with tubulin dsRNA. To determine whether the phenotypic changes observed after injection of dsRNA:tubulin were due to inhibition of tubulin gene expression, immunolabeling was carried out 19-24h post injection (Fig. 4). At this stage, dsRNA:control-injected cells had usually passed the two-cell embryo stage. Immunolabelling patterns of $\alpha$-tubulin typical of those found in other studies (e.g. Bisgrove and Kropf 2001; Corellou et al. 2005) were detected in all of the dsRNA:control-injected individuals, regardless of the developmental stage. Microtubules were observed in abundance in both the thallus and the rhizoid area in the perinuclear region, with perinuclear microtubules orientated perpendicular to the position of the future cell division plane (Fig. 4c, d). The same pattern of microtubule organisation was observed in uninjected zygotes .

The $\alpha$-tubulin immunolabeling patterns of dsRNA:tubulin-injected zygotes differed dramatically from those of dsRNA:control injected and uninjected zygotes. Microtubules were much less abundant in dsRNA:tubulin treated individuals than in dsRNA:control and uninjected Fucus zygotes. The extensive microtubule arrays seen in the apical area of control samples were absent in dsRNA:tubulin-injected zygotes and only highly localised condensed nuclear accumulations were apparent (Fig. 4a, b). Occasionally, microtubule labelling could 
still be observed in the rhizoid region of the zygote but was less pronounced compared to the controls. Reduced tubulin immunostaining was not due to displacement of microtubules to another part of the cell since the entire volume of the cell was analysed. We measured tubulin immunofluorescence and microtubule area as an proxy for $\alpha$-tubulin abundance since more direct immunoblot quantification of $\alpha$-tubulin protein or qPCR measurement of $\alpha$-tubulin transcript abundance were not feasible on the limited amount of injected material available in this study. Fluorescence levels, represented as mean grey values of immunolabeled zygotes injected with dsRNA:tubulin, were significantly lower compared to dsRNA:control injected individuals and uninjected zygotes (Fig. 5a). The relative area of microtubules in dsRNA:tubulin treated individuals was also significantly smaller than in dsRNA:control treated and uninjected embryos (Fig. 5b).

In the putative polyspermic zygotes, which showed aberrant but symmetrical cell division planes, normal abundances of microtubules with characteristic perinuclear organisation, were detected following immunostaining (Fig. S3), rather than the reduced levels of microtubules characteristic of dsRNA:tubulin-injected embryos (see Fig. 4).

Silencing of $\beta$-actin is maintained in F. serratus embryos over a period of at least three months. The rapid senescence of embryos injected with dsRNA $\alpha$-tubulin did not allow an assessment of the persistence of RNAi knock down in the Fucus embryo. However in addition to targeting $\alpha$-tubulin in our RNAi experiments we also targeted the highly abundant mRNA of the single copy $\beta$-actin gene. In $75.9 \%$ of the dsRNA:actin injected embryos the basal rhizoid had thickened by $48 \mathrm{~h}$ and there was little or no rhizoid growth after $72 \mathrm{~h}$ (Fig. 6). This response was never observed in dsRNA:control injected embryos. The severity of this phenotype increased over 12 weeks and was typified by distension and enlargement of cells which often protruded from the embryo surface (Fig. 7). The dsRNA:actin injected embryos 
1 showed no signs of senescence during the experiment; they maintained their pigmentation and

2 there was no visible breakdown in cellular structure. The progressive nature of the observed

3 phenotype and the lack of senescence suggests that actin silencing was maintained during the

$4 \quad 12$ weeks that the embryos were followed.

5

\section{Discussion}

In this study we show that injection of dsRNA is a viable method to knock down gene expression in zygotes and embryos of the brown alga $F$. serratus. Injection of dsRNA corresponding to an $\alpha$-tubulin gene resulted in growth inhibition and disruption of cell division during subsequent embryo development. The rhizoid failed to elongate and exhibited swelling. Cell division was either prevented completely or showed dramatic disruption of the normal regular division pattern. Immuno-staining showed that these effects on growth and cell division were correlated with disruption of the microtubule cytoskeleton and reduced levels of $\alpha$-tubulin in the cell. The phenotypes observed following injection of dsRNA:tubulin were very similar to those observed following treatment with the inhibitor nocodazole, which interferes with microtubule polymerisation. Previous studies have also reported growth inhibition and swelling of the rhizoid tip following continuous treatment with nocodazole (Corellou et al. 2005; Bisgrove and Kropf 1998). Moreover, a pulse treatment with nocodazole, applied $12 \mathrm{~h}$ after fertilization, has been shown to increase the number of embryos that have a misaligned first division plane (i.e. an aberrant division plane) and this was also associated with inhibition of elongation and a reduced growth rate (Bisgrove and Kropf 1998). Aberrant division planes were also observed when Sylvetia compressa zygotes were treated with monastrol $6 \mathrm{~h}$ after fertilization (Peters and Kropf 2006). Monastrol is an inhibitor of kinesin 5 motor proteins, which are involved in microtubule organisation (Miki et 
1 al. 2005). Other microtubule inhibitors such as colchicine have been shown to have similar

2 effects on cell division without affecting zygote polarization (e.g. Quatrano, 1973; Brawley 3 and Quatrano, 1979).

4 Significant growth inhibition, compared to control embryos was only manifest after $2 \mathrm{~d}$ in embryos injected with dsRNA:tubulin (see Fig. 1a). Effects on cell division were, however, detected earlier, at 19-24 h (i.e. at the first cell division) and reduced levels of $\alpha$-tubulin were also detected by this time (see Figs. 3,4). The lag period between injection and growth inhibition may have corresponded to the time necessary for the RNAi system to reduce $\alpha$ tubulin levels below a threshold necessary for growth, whereas cell division is likely to require higher tubulin levels and microtubule dynamics. This is consistent with observations that nocodazole treatment does not inhibit zygote polarization but does inhibit the first cell division (Corellou et al. 2005). The mRNAs encoding structural cytoskeletal proteins including $\alpha$-tubulin are maternally inherited and are amongst the most abundant mRNAs in the Fucus embryo as evidenced by representation in EST data sets (Masters et al. 1992; Pearson et al. 2010). Moreover, while there is no specific data available on the stability and turnover rates of tubulin and actin protein in Fucus embryos is very likely that low turnover and high stability contribute significantly to the observed lag between microinjection of dsRNA and phenotypic response. RNAi has been used successfully to silence maternal mRNAs in unfertilised animal oocytes and to study the role of developmental genes in Xenopus oocyte maturation and early embryogenesis (Svoboda et al. 2000). In this work we introduced dsRNA constructs into fertilised embryos of $F$. serratus because injection of unfertilised eggs is technically challenging (e.g. Roberts et al. 1994). Developing methodologies such as biolistic loading (Bothwell et al. 2008) of dsRNAs into unfertilised oocytes may lead to earlier silencing of maternally inherited and abundant mRNAs further increasing the potential of this approach in the Fucus system. 
1 The presence of substantially reduced, but detectable levels of $\alpha$-tubulin, rather than complete absence, in embryos injected with dsRNA:tubulin indicates a degree of incomplete silencing. Two contigs with homology to E. siliculosus $\alpha$-tubulin genes, designated TC_00471 and TC_00244, were identified in a F. serratus EST data set (see Fig. S1). The presence of at least two $\alpha$-tubulin genes in F. serratus has two main implications. First, long regions of identical sequence shared between genes, as seen between the 306 bp region spanning MB1 and the predicted protein coding sequence in both TC_00471 and TC_00244 would likely cause cosilencing of gene family members (Miki et al. 2005). This, combined with the high abundance of $\alpha$-tubulin mRNAs, could potentially saturate the silencing system leading to a delay in the onset of and incomplete penetration of the RNAi phenotype (Arvey et al. 2010). Xenopus embryos are especially prone to saturation of the RNAi system (Lund et al. 2011) and further experiments are needed to understand this phenomenon in Fucus embryos. Alternatively, the function of the targeted gene may be complemented by redundant functions of other gene family members that are not targeted by the specific RNAi, which could again result in delayed onset and attenuation of the phenotype. Future studies that utilise the observed long untranslated regions (3'UTRs) in many Fucus genes (Pearson et al. 2010) may offer a solution to the co-silencing problem. Targeting of silencing constructs to more variable 3' UTRs of OSrac mRNAs in rice resulted in silencing of specific gene family members whereas targeting to homologous of coding regions silenced multiple isoforms (Miki et al. 2005). Differentiating between these possibilities; co-silencing, saturation and redundancy will require detailed information concerning the complexity of the $\alpha$-tubulin complement of Fucus embryos and parallel quantification of multiple mRNAs.

The responses of individual embryos to injection of $\alpha$-tubulin dsRNA were quite variable, $33 \%$ exhibited no cell division, $42 \%$ exhibited aberrant cell divisions and in $25 \%$ normal cell division was observed. Our preliminary observations suggest that this variability in RNAi 
1

response is most likely the variable amount of dsRNA loaded into individual zygotes, as judged by the co-loading of fluorescent marker dyes with the dsRNA, since only poorlyloaded zygotes underwent normal development (results not shown). However, variability may be an inherent feature of RNAi in some systems. For example in the stramenopile oomycete, Phytophtora infestans, activation of RNAi by lipofection of dsRNA into protoplasts, which presumably leads to a more uniform loading than the microinjection system employed here for Fucus embryos, results in variable silencing both between individual organisms in a population and within different cells of a single organism (Whisson et al. 2005). Further RNAi studies in the Fucus embryo will benefit from accurate quantification of the introduced silenced dsRNA species.

In contrast to the eventual senescence over several days of dsRNA:tubulin-treated embryos, the phenotype induced after the introduction of dsRNA:actin into the F. serratus embryos persisted for 12 weeks even though the dsRNA:actin trigger molecule was introduced only transiently. Silencing of the aureochrome receptor in the stramenopile alga Vaucheria frigida was maintained for over 6 months after the microinjection of a transient dsRNA trigger molecule (Takahashi et al. 2007). The recently sequenced genome of the brown alga $E$. siliculosus provides evidence for a mechanism for the prolonged maintenance of the RNAi phenotype. E. siliculosus contains components of the RNAi machinery including homologs of Dicer, Argonaute and two RNA-dependent RNA polymerases (RDRP). In the green plant Arabidopsis thaliania, the RDRP SDE1 is required for amplification and maintenance of gene silencing mediated by a transgene (Dalmay et al. 2000), RDRP may play a similar role in maintenance of RNAi gene silencing in brown algae.

A caveat to interpreting our actin RNAi experiments is that the levels of the $\beta$-actin protein were not determined in individual embryos. The phenotypes of $F$. serratus embryos injected with dsRNA-actin however are wholly consistent with current models of $\beta$-actin function in 
1 fucoid algae. Moreover, the different phenotypes observed in response to dsRNA:tubulin and

2 dsRNA:tubulin microinjection strongly imply that the observed effects are due to specific

3 gene knock down rather than non-specific effects on gene expression.

4

In dsRNA:actin-treated $F$. serratus embryos compromised cell wall deposition is consistent with the distended appearance of the cells in these embryos. Low concentrations of the actin depolymerising compound latrunculin $\mathrm{B}$ have been shown to block cell division and polarisation in F. serratus embryos (Bothwell et al. 2008). RNAi-mediated reduction of $\beta$ actin protein below a critical level would be expected to similarly compromise cell division, and is also consistent with reduced rhizoid length after $72 \mathrm{~h}$ and the appearance of enlarged cells throughout the embryo.

The demonstration that RNAi is functional and maintained for long periods in the F. serratus embryo is the first example of targeted gene silencing in a brown macroalga and paves the way for studies into the molecular basis of the phenomenon. Using microinjection, it was possible to inject up to $60 \mathrm{~F}$. serratus zygotes in a single session of approximately $4 \mathrm{~h}$, sufficient to allow the reproducibility of a response to be accessed and statistical analyses of phenotyping data to be carried out. The protocol described here opens up the possibility of analysing the functions of specific Fucus genes during early development. Moreover, the demonstration that injection of dsRNA can be used to knock down gene expression in a brown alga suggests that RNAi may be a viable technique for gene function analysis in other brown algae. It will be particularly productive, for example, to adapt the method described here for the filamentous brown alga Ectocarpus, for which a complete genome sequence in available (Cock et al. 2010a,b) together with a broad range of genetic, transcriptomic, 
1 proteomic and metabolomic tools (Heesch et al. 2010; Coelho et al. 2011; Peters et al. 2008;

2 Dittami et al. 2009; Ritter et al. 2010; Dittami et al. 2011).

3

\section{Acknowledgements}

5 This work was supported by the Interreg IV Program France (Channel)-England (project

6 Marinexus), the Centre National de Recherche Scientifique, the University Pierre and Marie

7 Curie and the Marine Genomics Europe Network of Excellence.

8 


\section{References}

Arvey, A., Larsson, E., Sander, C., Leslie, C.S., Marks, D.S. 2010. Target mRNA abundance dilutes microRNA and siRNA activity. Mol. Syst. Biol. 6:363.

Bisgrove, S.R. 2007. Cytoskeleton and early development in fucoid algae. J. Integrative Plant Biol. 49: 1192-1198.

Bisgrove, S.R., Henderson, D.C., Kropf, D.L. 2003. Asymmetric division in fucoid zygotes is positioned by telophase nuclei. Plant Cell 15: 854-862.

Bisgrove, S.R., Kropf, D.L. 1998. Alignment of centrosomal and growth axes is a late event during polarization of Pelvetia compressa zygotes. Dev. Biol. 194: 246-256.

Bisgrove, S.R., Kropf, D.L. 2001. Asymmetric cell division in fucoid algae: a role for cortical adhesions in alignment of the mitotic apparatus. J. Cell Sci. 114: 4319-4328.

Bothwell, J.F.H., Brownlee, C., Hetherington, A.M., Ng, C.K.Y. Wheeler, G.L. McAinsh, M.R. 2006. Biolistic delivery of $\mathrm{Ca}^{2+}$ dyes into plant and algal cells. Plant J. 46:327335.

Bothwell JH, Kisielewska J, Genner MJ, McAinsh MR, Brownlee C. 2008. $\mathrm{Ca}^{2+}$ signals coordinate zygotic polarization and cell cycle progression in the brown alga Fucus serratus. Development 135(12): 2173-2181.

Bouget, F.Y., Berger, F., Brownlee, C. 1998. Position dependent control of cell fate in the Fucus embryo: role of intercellular communication. Development 125: 1999-2008.

Brawley, S.H. 1987. A sodium-dependent, fast block to polyspermy occurs in eggs of fucoid algae. Devel. Biol .124: 390-397.

Brawley, S.H., Quatrano, R.S. 1979. Effects of microtubule inhibitors on pronuclear migration and embryogenesis in Fucus distichus (Phaeophyta). J. Phycol. 15:266-272.

Brownlee, C., Bouget, F.Y. 1998. Polarity determination in Fucus: from zygote to multicellular embryo. Semin. Cell Dev. Biol. 9: 179-185. 
1 Brownlee, C., Bouget, F.Y., Corellou, F. 2001. Choosing sides: establishment of polarity in zygotes of fucoid algae. Semin. Cell. Dev. Biol.12: 345-351.

Carthew, R.W., Sontheimer, E.J. 2009. Origins and Mechanisms of miRNAs and siRNAs. Cell 136: 642-655.

Cerutti, H., Ma, X., Msanne, J., Repas, T. 2011. RNA-mediated silencing in Algae: biological roles and tools for analysis of gene function. Eukaryot. Cell 10: 1164-1172.

Chapman, E.J., Carrington, J.C. 2007. Specialization and evolution of endogenous small RNA pathways. Nat. Rev. Genet. 8: 884-896.

Cock. J.M., Sterck, L., Rouzé, P., Scornet, D., Allen, A., Amoutzias, G., Anthouard, V., Artiguenave, F., Aury, J., Badger, J., Beszteri, B., Billiau, K., Bonnet, E., Bothwell, J., Bowler, C., Boyen, C., Brownlee, C., Carrano, C., Charrier, B., Cho, G., Coelho, S., Collén J, Corre E, Da Silva C, Delage L, Delaroque N, Dittami S, Doulbeau S, Elias, M., Farnham, G., Gachon, C., Gschloessl, B., Heesch, S., Jabbari, K., Jubin, C., Kawai, H., Kimura, K., Kloareg, B., Küpper, F., Lang, D., Le Bail, A., Leblanc, C., Lerouge, P., Lohr, M., Lopez, P., Martens, C., Maumus, F., Michel,G., MirandaSaavedra, D., Morales, J., Moreau, H., Motomura, T., Nagasato, C., Napoli, C., Nelson, D., Nyvall-Collén, P., Peters, A., Pommier, C., Potin, P., Poulain, J., Quesneville, H., Read, B., Rensing, S., Ritter, A., Rousvoal, S., Samanta, M., Samson, G., Schroeder, D., Ségurens, B., Strittmatter, M., Tonon, T., Tregear, J., Valentin, K., von Dassow, P., Yamagishi, T., Van de Peer,Y., Wincker, P. 2010. The Ectocarpus genome and the independent evolution of multicellularity in brown algae. Nature 465: 617-621.

Cock, J.M., Coelho, S.M., Brownlee, C., Taylor, A.R. 2010. The Ectocarpus genome sequence: insights into brown algal biology and the evolutionary diversity of the eukaryotes. New Phytol.188: 1-4. 
1 Coelho, S.M., Godfroy, O., Arun, A., Le Corguillé, G., Peters, A.F., Cock, J.M. 2011. OUROBOROS is a master regulator of the gametophyte to sporophyte life cycle transition in the brown alga Ectocarpus. Proc. Natl. Acad. Sci. U S A 108: 1151811523

Corellou, F., Coelho, S.M., Bouget, FY., Brownlee, C. 2005. Spatial re-organisation of cortical microtubules in vivo during polarisation and asymmetric division of Fucus zygotes. J. Cell Sci. 118: 2723-2734.

Dalmay,T., Hamilton, A., Rudd, S., Angell, S., Baulcombe, D.C. 2000. An RNA-dependent RNA polymerase gene in Arabidopsis is required for posttranscriptional gene silencing mediated by a transgene but not by a virus. Cell 101:543-553.

De Riso, V., Raniello, R., Maumus, F., Rogato, A., Bowler, C., Falciatore, A. 2009. Gene silencing in the marine diatom Phaeodactylum tricornutum. Nucleic Acids Res. 37: e96.

Dittami, S., Scornet, D., Petit, J., Ségurens, B., Da Silva, C., Corre, E., Dondrup, M., Glatting, K., König, R., Sterck, L., Rouzé, P., Van de Peer, Y., Cock, J., Boyen, C., Tonon, T. 2009. Global expression analysis of the brown alga Ectocarpus siliculosus (Phaeophyceae) reveals large-scale reprogramming of the transcriptome in response to abiotic stress. Genome Biol. 10: R66.

Dittami, S.M., Gravot, A., Renault, D., Goulitquer, S., Eggert, A., Bouchereau, A., Boyen, C., Tonon, T. 2011. Integrative analysis of metabolite and transcript abundance during the short-term response to saline and oxidative stress in the brown alga Ectocarpus siliculosus. Plant Cell Environ, 34: 629-642.

Fowler, J.E., Vejlupkova, Z., Goodner, B.W, Lu, G., Quatrano, R.S. 2004. Localization to the rhizoid tip implicates a Fucus distichus Rho family GTPase in a conserved cell polarity pathway. Planta 219: 856-866. 
1 Goodner, B., Quatrano, R.S. 1993. Fucus Embryogenesis: A Model to Study the 2 Establishment of Polarity. Plant Cell 5: 1471-1481.

Hable, W.E., Miller, N.R., Kropf, D.L. 2003. Polarity establishment requires dynamic actin in fucoid zygotes. Protoplasma 221: 193-204.

Hable, W.E., Kropf, D.L. 2005. Studies of the Arp2 protein and actin nucleation in fucoid zygotes. Cell Motil. Cytoskel. 61:9-20.

Heesch, S., Cho, G.Y., Peters, A.F., Le Corguillé, G., Falentin, C., Boutet, G., Coëdel, S., Jubin, C., Samson, G., Corre, E., Coelho, S.M., Cock, J.M. 2010. A sequence-tagged genetic map for the brown alga Ectocarpus siliculosus provides large-scale assembly of the genome sequence. New Phytol 188: 42-51.

Huang, A., He, L., Wang, G. 2011. Identification and characterization of microRNAs from Phaeodactylum tricornutum by high-throughput sequencing and bioinformatics analysis. BMC Genomics 12: 337.

Katsaros , C., Karyophyllis, D., Galatis, B. 2006 Cytoskeleton and morphogenesis in brown algae. Ann. Bot. 97: 679-693.

Klarzynski, O., Descamps, V., Plesse, B., Yvin, J.C., Kloareg, B., Fritig, B. 2003. Sulfated fucan oligosaccharides elicit defense responses in tobacco and local and systemic resistance against tobacco mosaic virus. Mol. Plant. Microbe Interact. 16: 115-122.

Lund, E., Sheets, M.D., Imboden, S.B., Dahlberg, J.E. 2011. Limiting Ago protein restricts RNAi and microRNA biogenesis during early development in Xenopus laevis. Genes. Dev. 25:1121-31

Masters, A.K., Shirras, A.D., Hetherington, A.M. 1992 Maternal Messenger RNA and early development in Fucus serratus. Plant J. 8: 619-622.

McHugh DJ 2003. A guide to seaweed industry. In: FAO ed. FAO Fisheries Technical Paper No 441. Rome, Italy: FAO. 
1 Miki, H., Okada, Y., Hirokawa, N. 2005. Analysis of the kinesin superfamily: insights into structure and function. Trends Cell Biol. 15: 467-476.

Motomura, T., Nagasato, C. 2004. The first spindle formation in brown algal zygotes. Hydrobiologica 512: 171-176.

Norden-Krichmar, T.M., Allen, A.E., Gaasterland, T., Hildebrand, M. 2011. Characterization of the small RNA transcriptome of the diatom, Thalassiosira pseudonana. PLoS One 6: e22870.

Pearson, G.A., Hoarau, G., Lago-Leston, A., Coyer, J.A., Kube, M., Reinhardt, R., Henckel, K., Serrao, E.T.A., Corre, E. Olsen, J.L. (2010) An expressed sequence tag analysis of the intertidal brown seaweeds Fucus serratus (L.) and F. vesiculosus (L.) (Heterokontophyta, Phaeophyceae) in response to abiotic stressors. Mar. Biotechnol. 12: $195-213$

Peters, A.F., Scornet, D., Ratin, M., Charrier, B., Monnier, A., Merrien, Y., Corre, E., Coelho, S.M., Cock, J.M. 2008. Life-cycle-generation-specific developmental processes are modified in the immediate upright mutant of the brown alga Ectocarpus siliculosus. Development 135: 1503-1512.

Peters, N.T., Kropf, D.L. 2006. Kinesin-5 motors are required for organization of spindle microtubules in Silvetia compressa zygotes. BMC Plant Biol. 6: 19.

Peters, N.T., Kropf, D.L. 2010. Asymmetric microtubule arrays organize the endoplasmic reticulum during polarity establishment in the brown alga Silvetia compressa. Cytoskeleton (Hoboken) 67: 102-111.

Ritter, A., Ubertini, M., Romac, S., Gaillard, F., Delage, L., Mann, A., Cock, J.M., Tonon, T., Correa, J.A., Potin, P. 2010. Copper stress proteomics highlights local adaptation of two strains of the model brown alga Ectocarpus siliculosus. Proteomics 10: 20742088. 
1 Quatrano, R.S. 1973. Separation of processes associated with differentiation of 2-celled Fucus

2 embryos. Devel. Biol. 30:209-213.

Roberts, S.K., Gillot, I., Brownlee, C. 1994 Cytoplasmic calcium and Fucus egg activiation. Development 120: 155-163.

Shaw, S., Quatrano, R.S 1996. The role of targeted secretion in the establishment of cell polarity and the orientation of the division plane in Fucus zygotes. Development 122: 2623-2630.

Svoboda, P., Stein, P., Hayashi, H., Schultz, R.M. 2002. Selective reduction of dormant maternal mRNAs in mouse oocytes by RNA Interference. Development 127, 41474156.

Takahashi, F., Yamagata, D., Ishikawa, M., Fukamatsu, Y., Ogura,Y., Kasahara, M., Kiyosue, T., Kikuyama, M., Wada, M., Kataoka, H. 2007. AUREOCHROME, a photoreceptor required for photomorphogenesis in stramenopiles. Proc. Natl. Acad. Sci. U S A 104: 19625-19630.

Voinnet, O. 2009. Origin, biogenesis, and activity of plant microRNAs. Cell 136(4): 669-687.

Whisson, S.C., Avrova, A.O., Van West, P., Jones, J.T. 2005. A method for doublestranded RNA-mediated transient gene silencing in Phytophthora infestans. Molec. Plant Pathol. 6: 153-163 


\section{Figure Legends}

2 Figure 1. Growth and morphology of $F$. serratus embryos following microinjection of zygotes with dsRNA:tubulin. (a) Embryo lengths 1, 2 and 3 days post-injection (PI). Data represent geometric means of two independent experiments. Error bars show standard deviations. dsRNA:tub: Fucus zygotes injected with dsRNA:tubulin (n=15); dsRNA:cont: Fucus zygotes injected with dsRNA:control (n=23); uninj: uninjected Fucus zygotes that were in the same dish as injected zygotes $(\mathrm{n}=18)$. $(\mathrm{b}-\mathrm{d})$ representative images of $F$. serratus embryos at 3 days PI. dsRNA:tubulin-injected embryos showed no complete cell divisions and growth was arrested 1-2 days PI (b) whereas dsRNA:control-injected (c) and uninjected zygotes (d) exhibited multiple cell divisions and elongated rhizoids.

Figure 2. Phenotypes of nocodazole-treated or dsRNA:tubulin-injected $F$. serratus embryos. (a) Control incubation in $0.02 \%$ DMSO. (b-d) Bright field images of representative embryos 3 days after treatment with $1 \mu \mathrm{g} \mathrm{mL} \mathrm{m}^{-1}$ nocodazole. (e-h) representative embryos 3 days after injection with dsRNA:control (e) or dsRNA:tubulin (f-h). Scale bars $25 \mu \mathrm{m}$

Figure 3. Representative images of the four categories of cell plate phenotypes observed in dsRNA:tubulin-injected Fucus serratus embryos. (a) Normal division pattern. (b) Absence of cell plate formation. (c) Aberrant symmetrical division pattern. (d) Aberrant asymmetrical division patterns. Arrowheads in (a, c and d) indicate cell plates. (e) Proportions of embryos in each phenotype category following microinjection of either dsRNA:tubulin $(n=55)$, dsRNA:control $(n=26)$ or uninjected $(n=21)$. Data derive from 5 independent microinjection experiments. Embryos were observed $24 \mathrm{~h}$ after injection. 
1 Figure 4. Planar z-stack projections of confocal sections through $\alpha$-tubulin immunolabelled

2 Fucus serratus embryos $24 \mathrm{~h}$ after microinjection of double stranded RNA. Two representative embryos are shown for each treatment. (a, b) dsRNA:tubulin-injected embryos. Highly localized and condensed microtubules are visible. Note the aberrant cell divisions in (a). (c, d) dsRNA:control-injected and (e, f) uninjected embryos show extensive microtubule arrays in perinuclear and rhizoid regions. Scale bars $50 \mu \mathrm{m}$

Figure 5. Quantification of microtubule fluorescence as a proxy of $\alpha$-tubulin content in immunolabelled Fucus serratus zygotes injected with either dsRNA: control (n=8), dsRNA:tubulin $(n=32)$ or uninjected $(n=9)$. Data represent mean values and standard deviation of three independent experiments. a) Mean gray value of the zygotes and b) relative microtubule areas. $\mathrm{a}^{* * *}$ indicates highly significant difference $(\mathrm{p}=0.01)$ between dsRNA:tubulin and uninjected zygotes and $b^{* *}$ indicates significant difference between dsRNA;tubulin and dsRNA: control injected zygotes $(\mathrm{p}<0.05$; tests: Kruskal Wallis and Dunn's multiple comparison post test).

Figure 6. Progression of the dsRNA:actin phenotype in F. serratus over 12 weeks. Embryo development post injection (PI) of zygotes with dsRNA:control (a, b, c) or dsRNA:actin (d, e, f, g) 48h PI (a, d), 21 d PI (b, e), 6 weeks PI (c, f) and 12 weeks PI (g). The first evidence of altered development in dsRNA:actin injected embryos was a reduction in the length and thickening of the rhizoid (indicated by arrows in (b)) by $48 \mathrm{~h}$ PI. At $21 \mathrm{~d}$ dsRNA:actin injected embryos contained many enlarged cells and shortened rhizoids (e) compared to dsRNA:control embryos (b). At 6 weeks embryos were still viable, producing occasional adventitious rhizoids (arrow in (f)). Apical hairs, apparent in dsRNA:control injected embryos (arrows in (c)) were always absent in dsRNA:actin injected embryos (f). Distended cells are apparent in dsRNA:actin injected embryos. By 12 weeks several of these distended cells 
1 visibly bulged out from the periphery of the dsRNA:actin injected embryos (g). At 12 weeks

2 dsRNA:actin injected embryos showed little further rhizoid elongation compared with $21 \mathrm{~d}$ or 342 d embryos.

4

$5 \quad$ Figure 7. Relative numbers of phenotypes of $F$. serratus embryos at 14 days after

6 microinjection with either dsRNA:control or dsRNA:actin. Embryos were scored according to

7 the following criteria. Normal development compared to uninjected embryos of the same age

8 (normal), failure to develop beyond initial polarisation and second cell division (stall), failure

9 
a
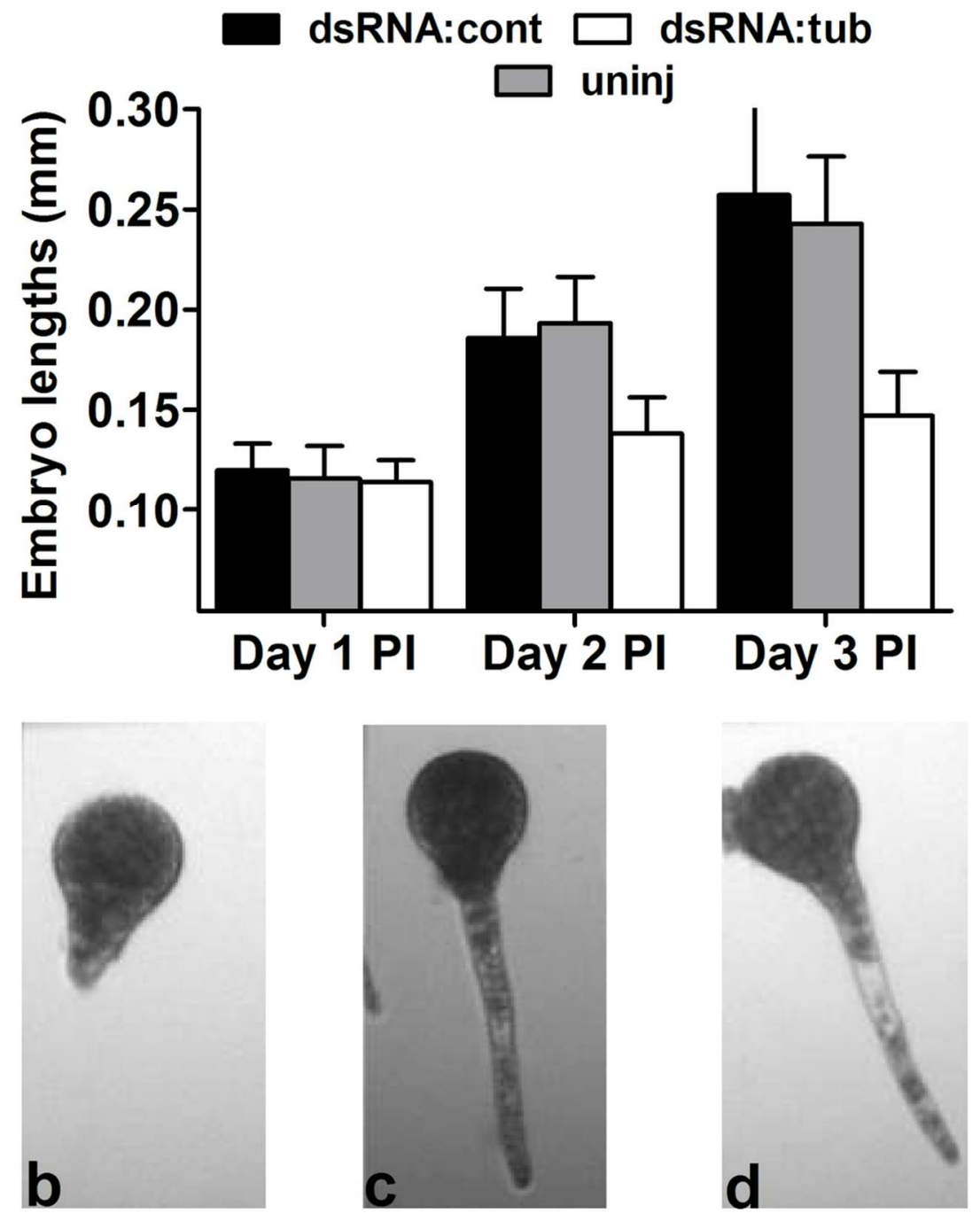

Figure 1. Growth and morphology of F. serratus embryos following microinjection of zygotes with dsRNA:tubulin. (a) Embryo lengths 1, 2 and 3 days post-injection (PI). Data represent geometric means of two independent experiments. Error bars show standard deviations. dsRNA:tub: Fucus zygotes injected with dsRNA:tubulin $(n=15)$; dsRNA: cont: Fucus zygotes injected with dsRNA:control $(n=23)$; uninj: uninjected

Fucus zygotes that were in the same dish as injected zygotes $(n=18)$. (b-d) representative images of $F$. serratus embryos at 3 days PI. dsRNA:tubulin-injected embryos showed no complete cell divisions and growth was arrested 1-2 days PI (b) whereas dsRNA:control-injected (c) and uninjected zygotes (d) exhibited multiple cell divisions and elongated rhizoids. $99 \times 122 \mathrm{~mm}(300 \times 300 \mathrm{DPI})$ 


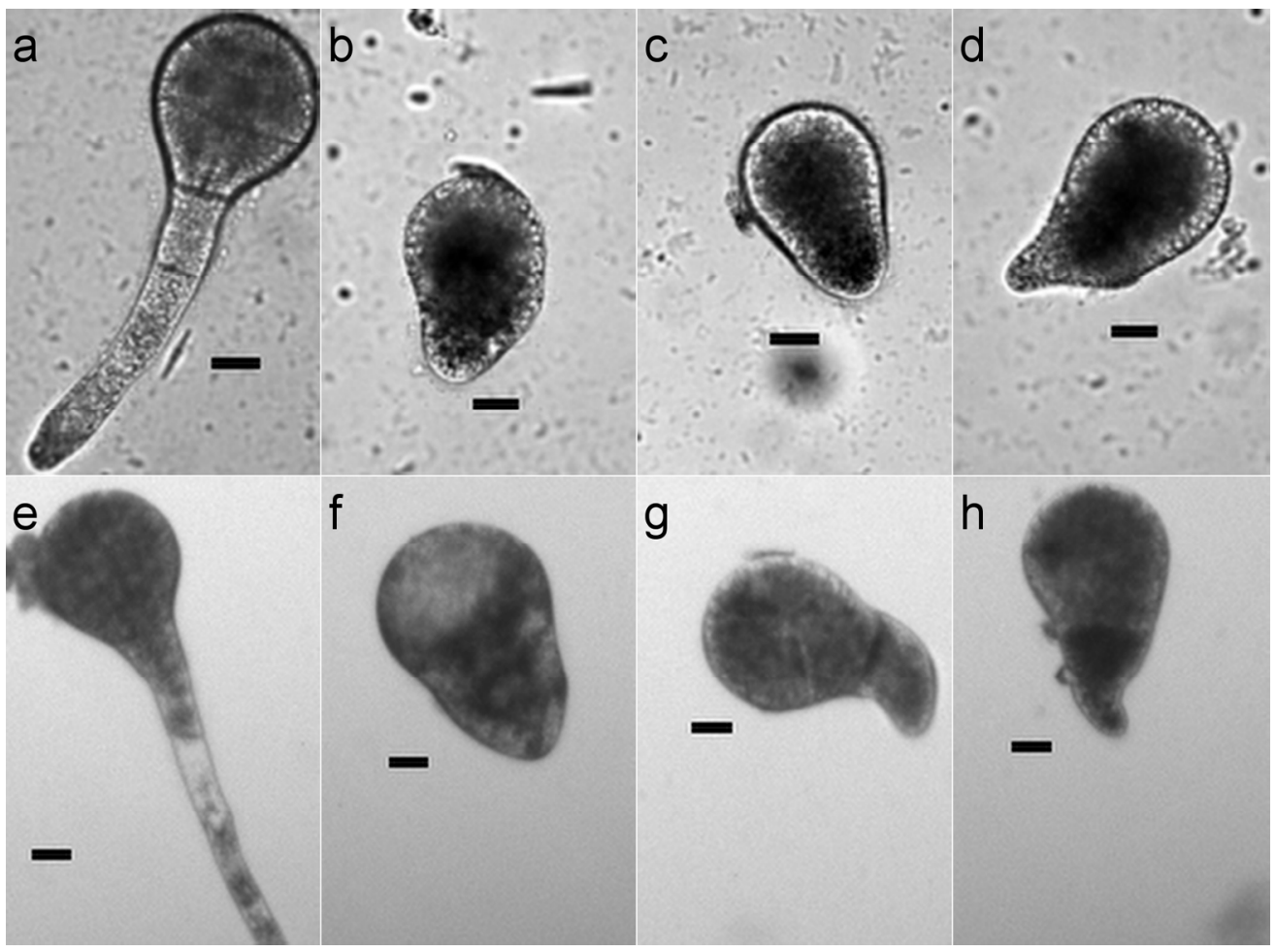

Figure 2. Phenotypes of nocodazole-treated or dsRNA:tubulin-injected F. serratus embryos. (a) Control incubation in $0.02 \%$ DMSO. (b-d) Bright field images of representative embryos 3 days after treatment with

$1 \mu \mathrm{g} \mathrm{mL}-1$ nocodazole. (e-h) representative embryos 3 days after injection with dsRNA:control (e) or dsRNA:tubulin (f-h). Scale bars $25 \mu \mathrm{m}$

$674 \times 499 \mathrm{~mm}(72 \times 72 \mathrm{DPI})$ 


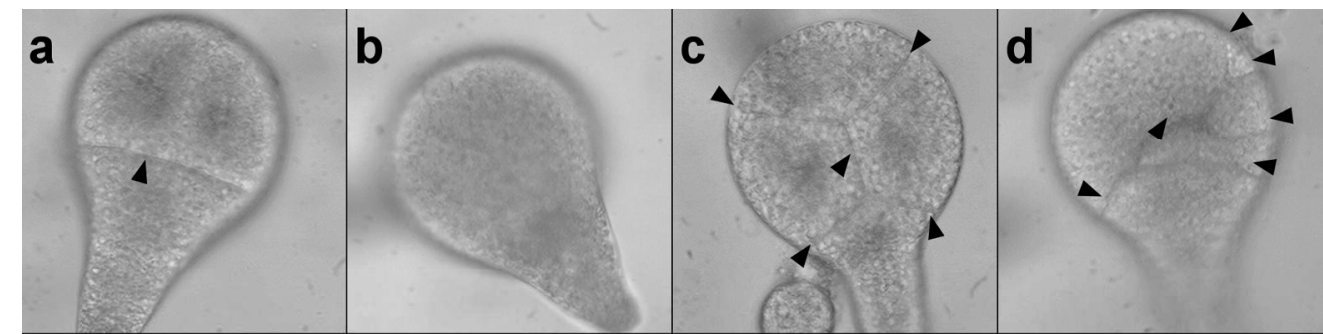

\section{e normal aberrant symmetrical $\square$ no cell plate $\square$ aberrant asymmetrical}

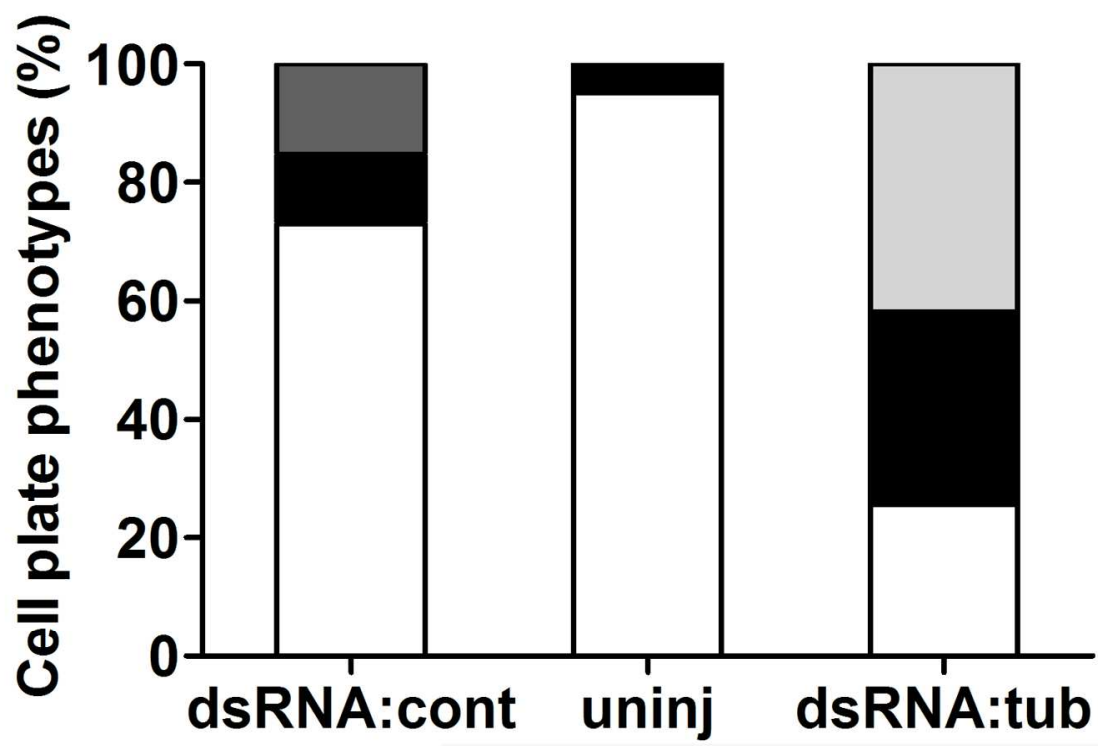

Figure 3. Representative images of the four categories of cell plate phenotypes observed in dsRNA:tubulininjected Fucus serratus embryos. (a) Normal division pattern. (b) Absence of cell plate formation. (c) Aberrant symmetrical division pattern. (d) Aberrant asymmetrical division patterns. Arrowheads in ( $a, c$ and d) indicate cell plates. (e) Proportions of embryos in each phenotype category following microinjection of either dsRNA:tubulin $(n=55)$, dsRNA:control $(n=26)$ or uninjected $(n=21)$. Data derive from 5 independent microinjection experiments. Embryos were observed $24 \mathrm{~h}$ after injection. 


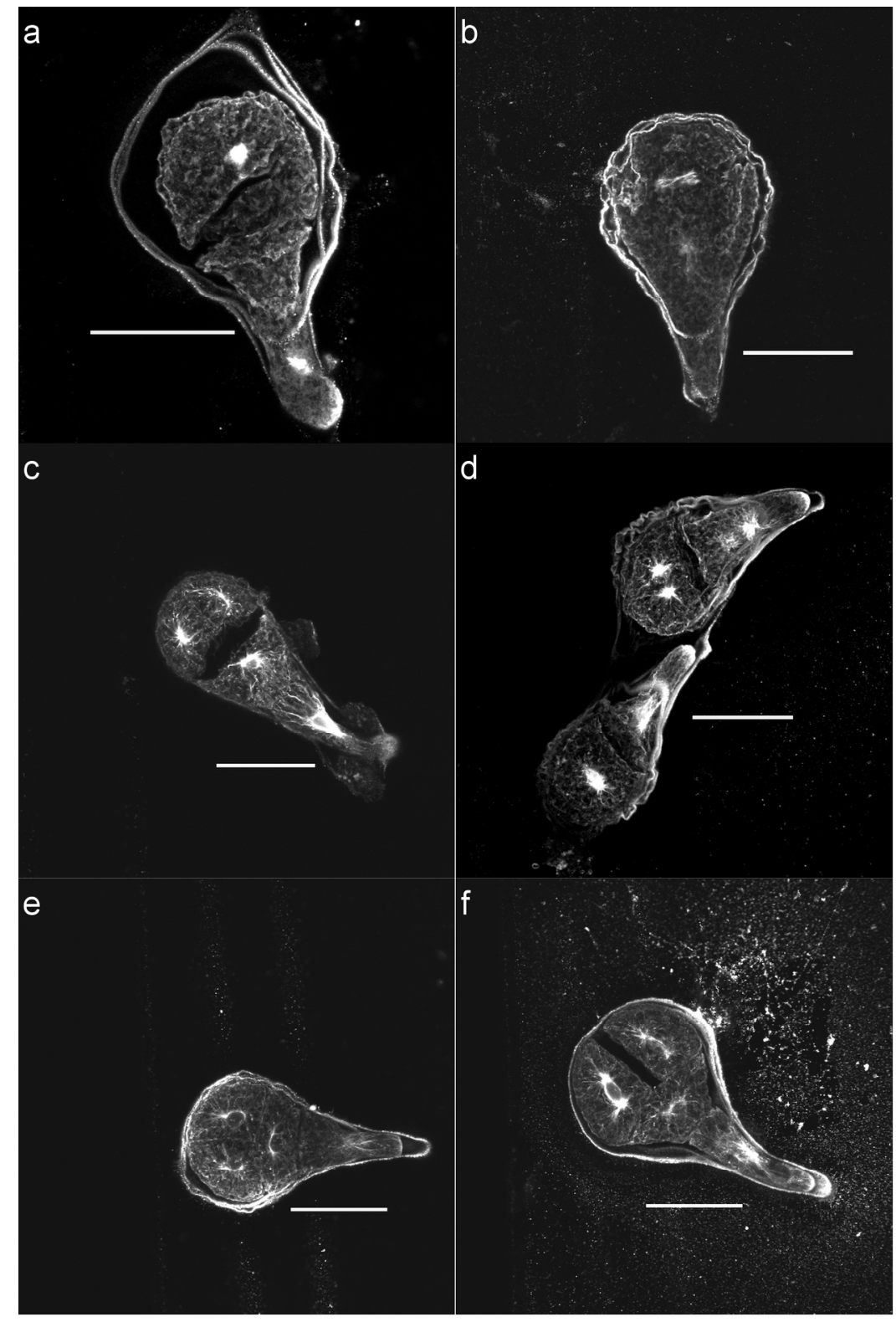

Figure 4. Planar z-stack projections of confocal sections through a-tubulin immunolabelled Fucus serratus embryos 24h after microinjection of double stranded RNA. Two representative embryos are shown for each treatment. (a, b) dsRNA:tubulin-injected embryos. Highly localized and condensed microtubules are visible. Note the aberrant cell divisions in $(a)$. (c, d) dsRNA:control-injected and $(e, f)$ uninjected embryos show extensive microtubule arrays in perinuclear and rhizoid regions. Scale bars $50 \mu \mathrm{m}$ $674 \times 1008 \mathrm{~mm}$ (72 x 72 DPI) 
a
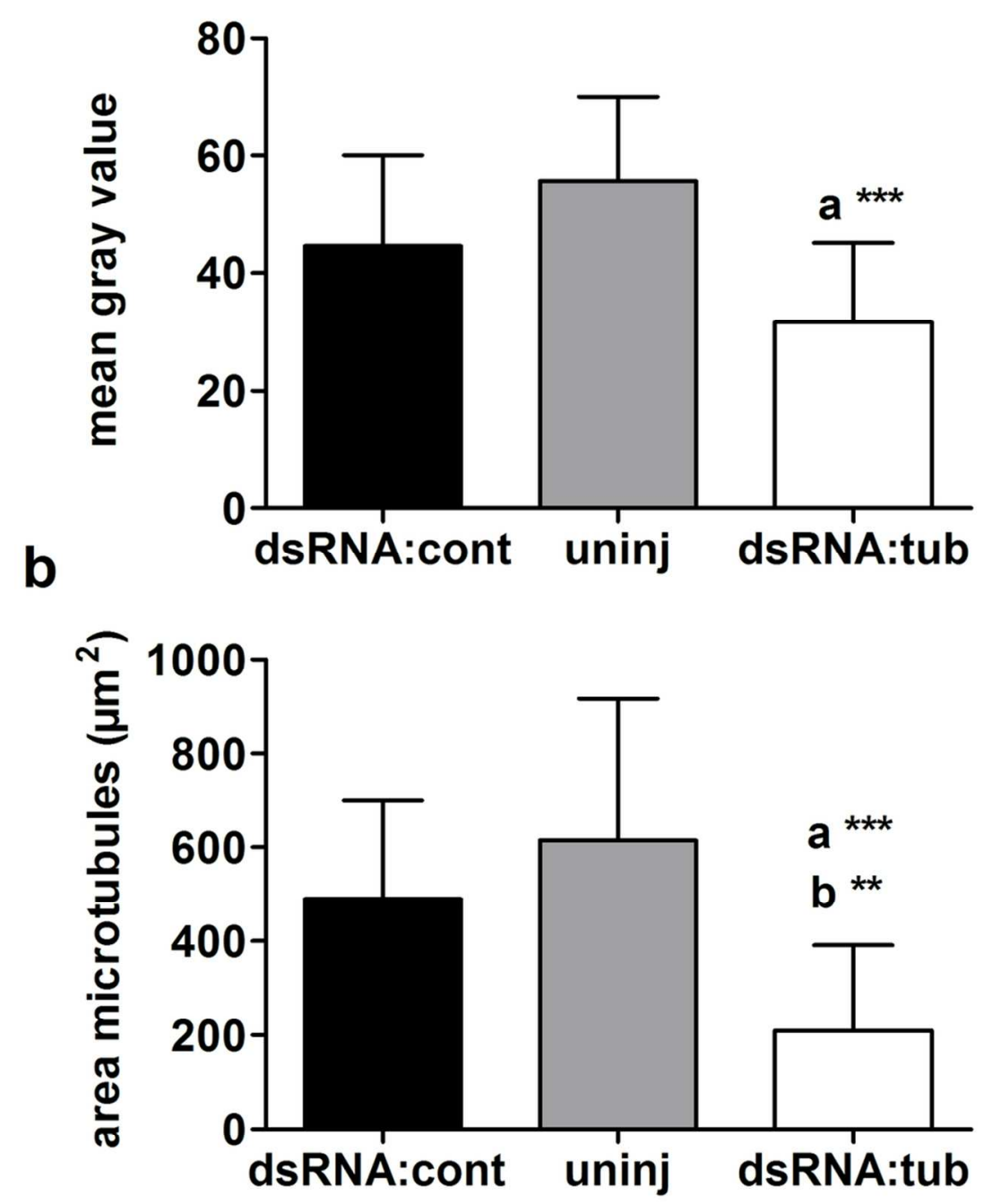

Figure 5. Quantification of microtubule fluorescence as a proxy of a-tubulin content in immunolabelled Fucus serratus zygotes injected with either dsRNA: control $(n=8)$, dsRNA:tubulin $(n=32)$ or uninjected $(n=9)$. Data represent mean values and standard deviation of three independent experiments. a) Mean gray value of the zygotes and b) relative microtubule areas. $a * * *$ indicates highly significant difference $(p=0.01)$ between dsRNA:tubulin and uninjected zygotes and $b * *$ indicates significant difference between dsRNA; tubulin and dsRNA: control injected zygotes ( $\mathrm{p}<0.05$; tests: Kruskal Wallis and Dunn's multiple comparison post test). $96 \times 115 \mathrm{~mm}(300 \times 300 \mathrm{DPI})$ 


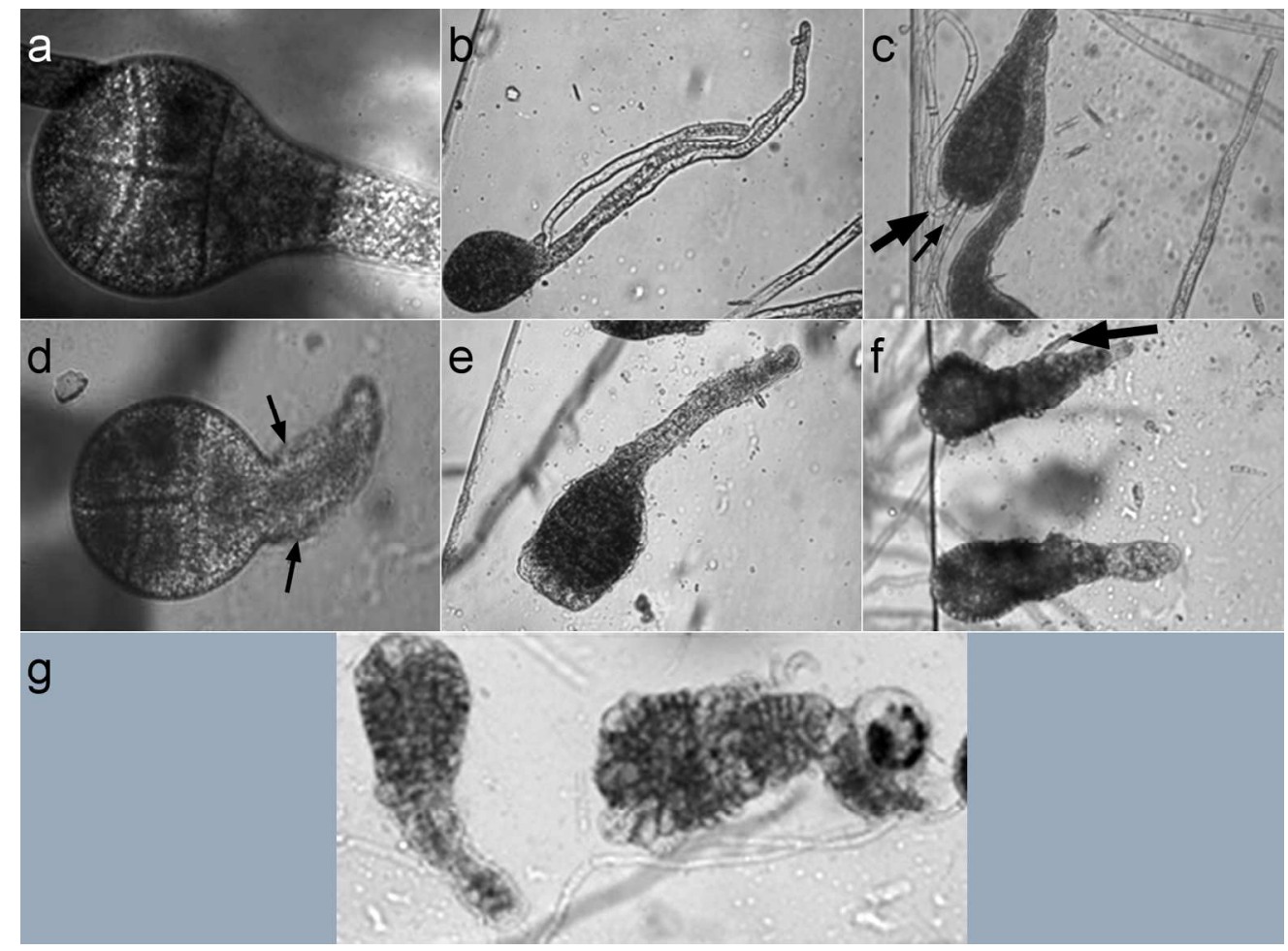

Figure 6. Progression of the dsRNA:actin phenotype in F. serratus over 12 weeks. Embryo development post injection (PI) of zygotes with dsRNA:control $(a, b, c)$ or dsRNA:actin (d, e, f, g) 48h PI (a, d), 21 d PI (b, e), 6 weeks PI $(c, f)$ and 12 weeks PI $(g)$. The first evidence of altered development in dsRNA:actin injected embryos was a reduction in the length and thickening of the rhizoid (indicated by arrows in (b)) by $48 \mathrm{~h}$ PI. At $21 \mathrm{~d}$ dsRNA:actin injected embryos contained many enlarged cells and shortened rhizoids (e) compared to dsRNA:control embryos (b). At 6 weeks embryos were still viable, producing occasional adventitious rhizoids (arrow in (f)). Apical hairs, apparent in dsRNA:control injected embryos (arrows in (c)) were always absent in dsRNA:actin injected embryos (f). Distended cells are apparent in dsRNA:actin injected embryos.

By 12 weeks several of these distended cells visibly bulged out from the periphery of the dsRNA:actin injected embryos $(\mathrm{g})$. At 12 weeks dsRNA:actin injected embryos showed little further rhizoid elongation compared with $21 \mathrm{~d}$ or $42 \mathrm{~d}$ embryos.

$674 \times 499 \mathrm{~mm}$ (72 x 72 DPI) 


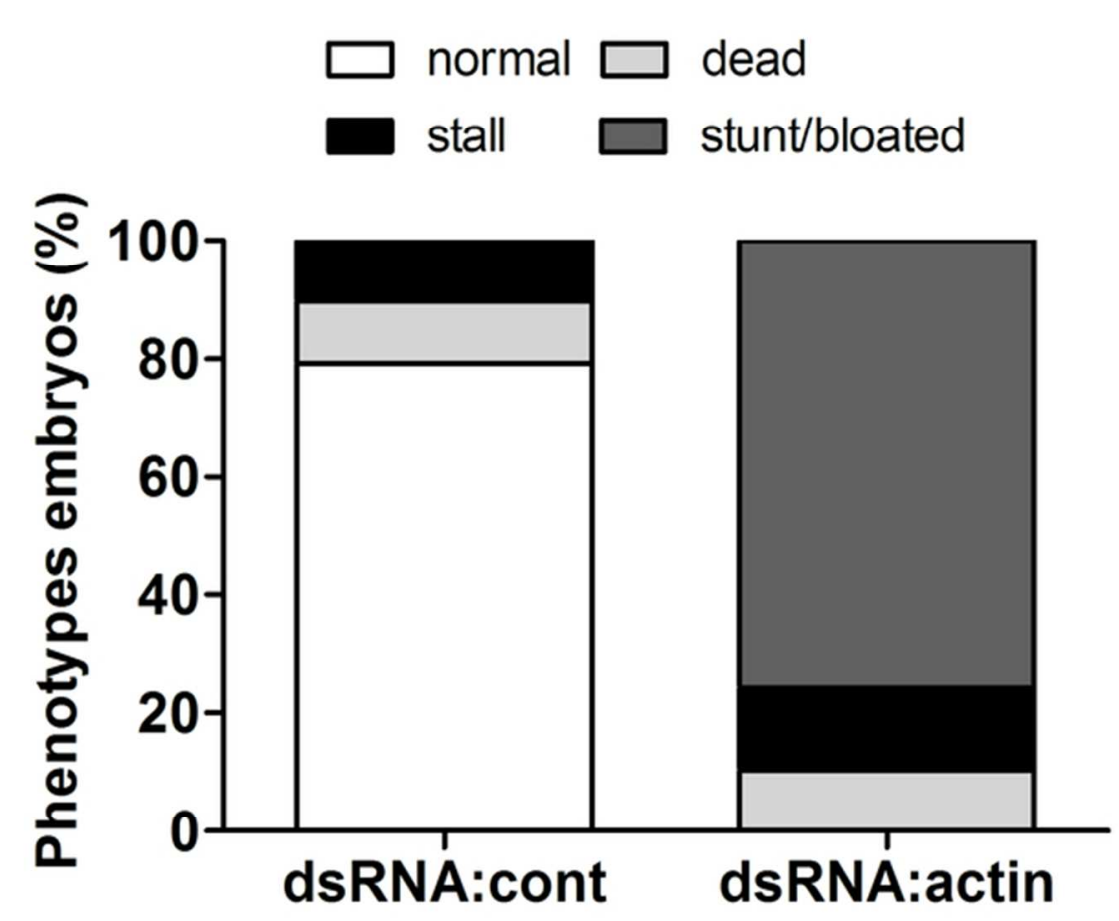

Figure 7. Relative numbers of phenotypes of F. serratus embryos at 14 days after microinjection with either dsRNA:control or dsRNA:actin. Embryos were scored according to the following criteria. Normal development compared to uninjected embryos of the same age (normal), failure to develop beyond initial polarisation and second cell division (stall), failure to polarise and undergo the first cell division (dead), thickening of the basal rhizoid at 48 hours, failure to elongate after 72 hours and development of enlarged distended cells, referred to as bloated cells, by 14 days (stunt/ bloated phenotype). The results are shown as a percentage of embryos exhibiting each phenotype using data derived from 4 (dsRNA:actin) and 5 (dsRNA:control) independent experiments, respectively ( $n=106$ embryos).

$59 \times 44 \mathrm{~mm}(300 \times 300$ DPI) 


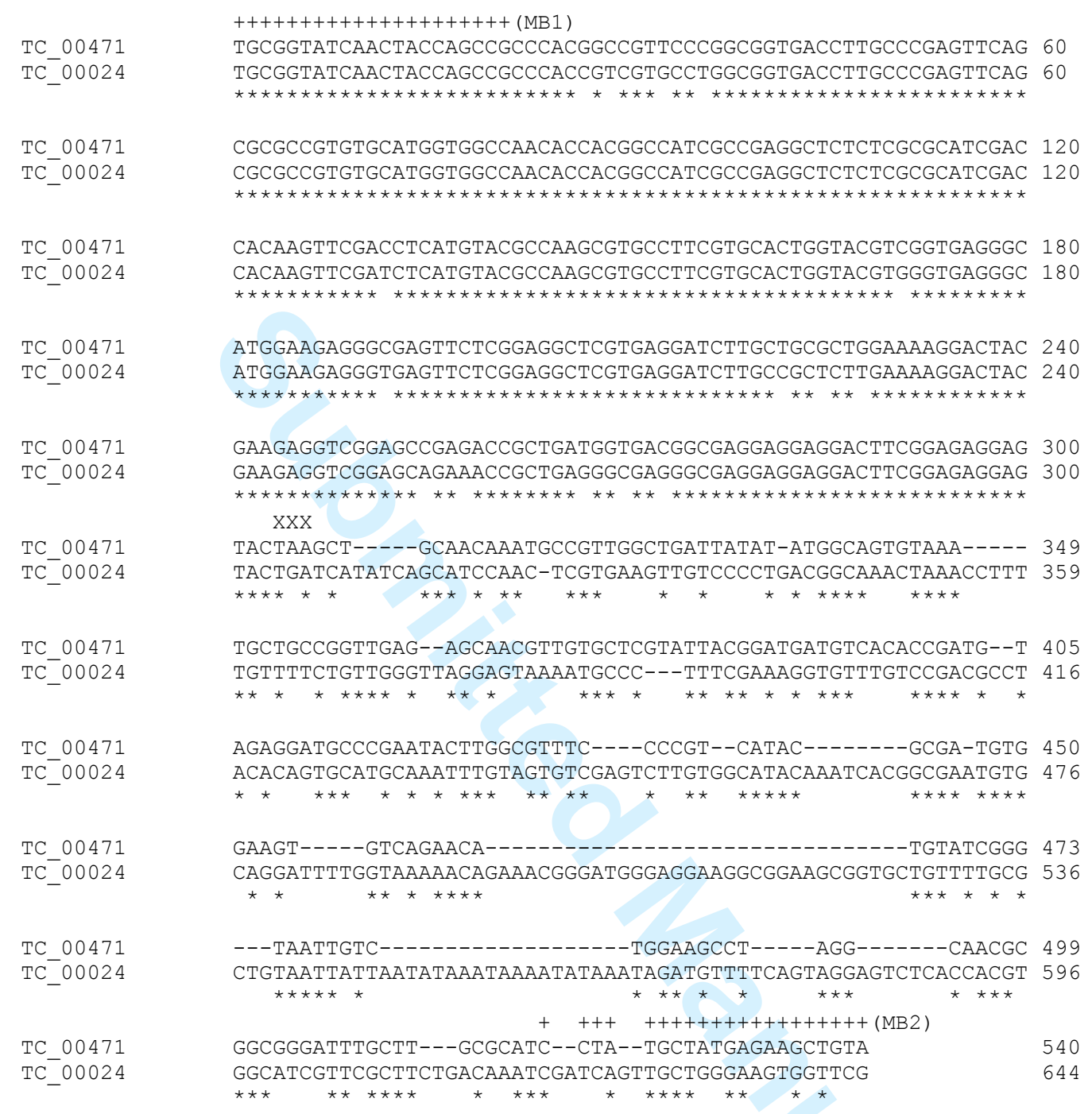

Figure S1: CLUSTAL 2.1 multiple sequence alignment of $\alpha$-tubulin sequences from a $F$. serrtus EST data set (Pearson et al. 2010). The alignment shows the region of TC_00471 and TC_00024 between the MB1 and MB2 primer binding sites (indicated by '+' above the sequence in the 5' and 3' regions of TC_00471). In the predicted protein coding sequence of TC_00471 and TC_00024 there are 15 nucleotide substitutions in 333 bases from the MB1 primer binding site to the predicted stop codon (Indicated by ' $\mathrm{XXX}$ '). The region spanning the stop codon to the MB2 primer binding site in TC_00471 is less well conserved and identity is low at the MB2 primer binding site. 
MB3 (f)

cactcttgtactccaccttccccaagaaccetccagctctctttagaacaaaactttatca

ACTFS1 (f)

gagaacaATGgcggacgaggacgtgcaagctttggtggtggacaacgggtccggcatgtgcaaggccg gcttcgccggtgacgacgcgccgcgtgccgttttcccttccatcgtgggtcgccccaagcaccccgga atcatggtcggcatggaccagaaggatgcctacgtgggcgacgaggcccagtccaagcgtggtgttct tactctcaataccccatcgagcacggcatcgtgaccaactgggacgacatggagaagatttggcacc acaccttctacaacgagctccgtgtagcccccgaggagcaccccgttttgctcacggaggcccccctc aaccccaaggccaacaaggagcgcatgactcagatcatgttcgagaccttcaacgtgcccgctatgta cgtcaacatccaggccgttctctccctctacgcctccggtcgtaccaccgggtgtgtgctcgattcgg gtgacggagtgtcccacacg

ACTFS2 ( $r)$

gtgcccatctacgaggggtacgctctaccccacgcaatcaaccgcctcgacctcgccgggcgtgacct gaccgataacctcatgaaggttttgaccgagcgtggttactccttcacgaccaccgcggagcgcgaga tcgttcgcgacatcaaggagaagctcacctacgtggcgctggacttcgaccaggagatgaagacggcc gcggagtcgtctcagcttgaaaagtcgtacgagctccccgacggaaacgtgatcgtgatcggcaacga gcgcttccgttgccctgaggttctcttccagccgtcgttcatcggaatggaatcttcgggcatccacg attgcaccttcaagaccatcatgaagtgcgacgtcgacatccgtaaggacctttacggcaacatcgta ctctcgggcggtaccaccatgttccccggcatcggcgagcggatgaccaaggagctgacggcactggc accttcgacaatgaagatcaaggttgtggcaccacccgagcggaaatactcggtgtggatcggtggtt ctatcctcgcgtcgctgtccacttccagcaaatgtggatttcgaaggcagagt

\section{MB4 ( $r)$}

acgatgagtctggcccgtccatcgttcaccgcaagtgcttcTAAaagccgaattccagcacactggcg gccgttactagtggatccgagctcggtaccaagcttggcgtaatcatggtcatagctgtgtgctagtt ggtttgctaaagaacccccctccaggggggggggggggtattgtcaccttaaagactttttgata

Figure S2: Sequence of the $F$. serratus $\beta$-actin mRNA that was used to construct templates for the generation of dsRNA in this work. The sequence includes the 69 nucelotide $5^{\text {'UTR }}$ region (underlined), the complete coding sequence delineated by ATG (Start) and TAA ( Stop) codons shown in capitalised text and the 157 nucleotide 3'UTR region ( underlined). The binding sites of forward (f) and reverse ( $r$ ) primers used to generate the template sequences for the 551bp (Actsf1 and Actfs2) and 1200bp ( MB3 and MB4) dsRNA actin constructs are shown in bold text. 

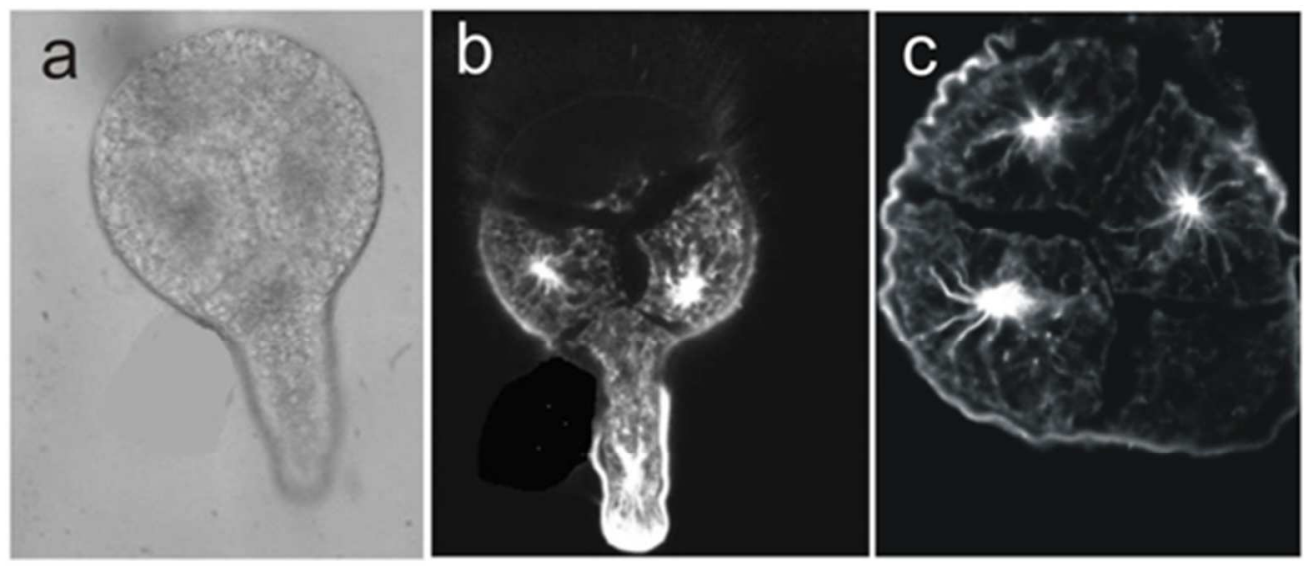

Figure S3. Labelling of a-tubulin in putative polyspermic F. serratus zygotes. (a) Brightfield image of a polyspermic embryo. (b, c) Representative a-tubulin labelling in similar zygotes. 